\title{
Laboratory-scale fracturing of cement and rock specimen by plasma blasting
}

\author{
${ }^{1}$ Department of Geophysics, Kangwon National University, 1 Kangwondaehakgil Chuncheon Gangwon-do 24341, Korea \\ ${ }^{2}$ Graduate School of Advanced Green Energy \& Environment, Handong Global University, 558 Handong-Ro Pohang Gyung-buk 37554, Korea; \\ *Corresponding author: E-mail: bajang@kangwon.ac.kr
}

(Received: June 5, 2019; Revised accepted: July 23, 2019)

https://doi.org/10.18814/epiiugs/2019/019017

Although hydraulic fracturing is the most commonly used method for fracturing of shale-gas-bearing rock, there are some problems with this method. As plasma blasting can fracture rock without these problems, laboratory-scale fracturing of cement and rock specimens by plasma blasting was performed to investigate the possibility of using this method in shale gas development. Specimens were fractured by plasma blasting under various stress conditions. First, specimens were fractured under uniform pressure, and the discharge energies required for fracturing and fracture development were investigated. As uniform pressure increased, the energy increased as a parabolic curve. Fewer fractures were developed as uniform pressure increased for the same discharge energy. Second, plasma blasting was performed for specimens subjected to three different stresses. Fractures both perpendicular and oblique to the minor stress direction were developed with a differential stress of $3 \mathrm{MPa}$; however, only fractures perpendicular to the direction of the minor stress were developed with an 8 MPa differential stress. More fractures with diverse directions were developed with the same stress conditions but higher energy. Several long fractures were developed by multiple low-energy blasts, the same result as for one highenergy blast. Proppants were injected effectively into fractures by plasma blasting, resulting in a hydraulic conductivity increase. In sandstone, the geological structure controlled the direction and characteristics of fracture development by plasma blasting. All these results indicate that plasma blasting can be a possible method for fracturing shale gas formation. However, more researches are necessary to apply this method in shale gas development in field.

\section{Introduction}

Shale gas, which is currently important in the energy market, is an unconventional natural gas. Shale gas deposits occur worldwide and will be the main natural gas resource in the future. The international Energy Agency predicted that energy demand in 2040 will be $25 \%$ higher than that in 2017. Natural gas demand will also increase as $1.6 \%$ per year up to 2040 (IEA, 2018). As shale has very low permeability, artificial fracturing methods must be applied for economic development of this type of rock (Perry and Lee, 2007). The most commonly used method is hydraulic fracturing, which can dramatically improve rock permeability and therefore the production of gas. However, there are some problems with application of hydraulic fracturing for fracturing rock. Because of the large water consumption, hydraulic fracturing cannot be undertaken in areas where large amounts of water cannot be supplied; in addition, as the injection fluid not only contains many chemicals but also induces seismicity, it is likely to cause environmental and safety problems (Osborn et al., 2011; Ellsworth, 2013; Kim et al., 2018; Wu et al., 2019). These problems have prompted the development of new fracturing methods that can replace hydraulic fracturing. Among the newly developed methods, plasma blasting is currently in the spotlight. This method has several advantages compared to hydraulic fracturing: it uses very small amounts of water and the possibility of environmental and safety problems is remarkably low (Chen et al., 2012).

Plasma blasting creates a plasma channel between two electrodes from the accumulated electrical energy and results in high heat, a shock wave and a volume increase of fluid by rapid evaporation if the discharge is generated within a fluid, which breaks the rock mass. This technology is classified into two types on the basis of the discharge method used. In the first type, the discharge is generated between two electrodes immersed within a fluid, and the shock wave propagates through the fluid to the surrounding rock, thus crushing the rock (Chen et al., 2012). In the second method, the rock is located between two electrodes in air. The plasma channels penetrate into the rock and the shock waves generated by the plasma channels cause a tensile force within rock, resulting in failure. In general, the tensile strength of rock is less than $10 \%$ of the compressive strength; therefore, the plasma channels that pass through the rock use less energy to break the rock than that for breaking by compression (Yan et al., 2016a). However, this method is applicable only dry conditions. As most wells are filled with water or fluid, the second method is not applicable within wells. 
As plasma blasting generally occurs within a few hundred nanoseconds, it is difficult to analyze the electrical characteristics accurately (Touya et al., 2006). Moreover, many researchers have used the same principle of plasma blasting, which is instantaneous discharge of energy accumulated in a capacitor, but various different electrical characteristics have been reported depending upon types of probes and switches used, and the type of measuring equipment (Hamelin et al., 1993; Pronko et al., 1993; Karpel-Vel-Leitner et al., 2005; Touya et al., 2006; Li et al., 2011; Zhu et al., 2013). The electrical characteristics during plasma blasting are well described in Touya et al. (2006) and Yan et al. (2016a).

Plasma blasting is an effective method to break solid material such as rock and concrete, and several studies have been conducted on breakage of rock by plasma blasting (Andres, 1994; Razavian et al., 2015). The magnitude of the shock wave was measured by a pressure sensor by Touya et al. (2006). Plasma blasting was performed above and inside a cement cylinder and fracturing was verified by permeability testing (Maurel et al., 2010; Chen et al., 2012). Hamelin et al. (1993), Wang et al. (2011), and Yan et al. (2016a, b) broke rock material by plasma blasting. In the 1970s, United States researchers con-

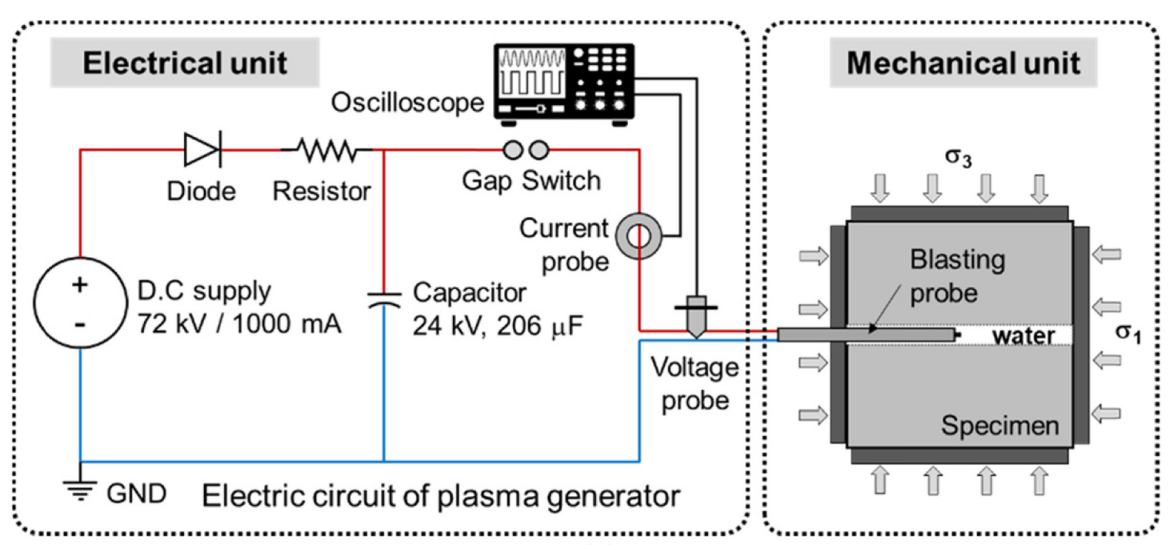

(a)

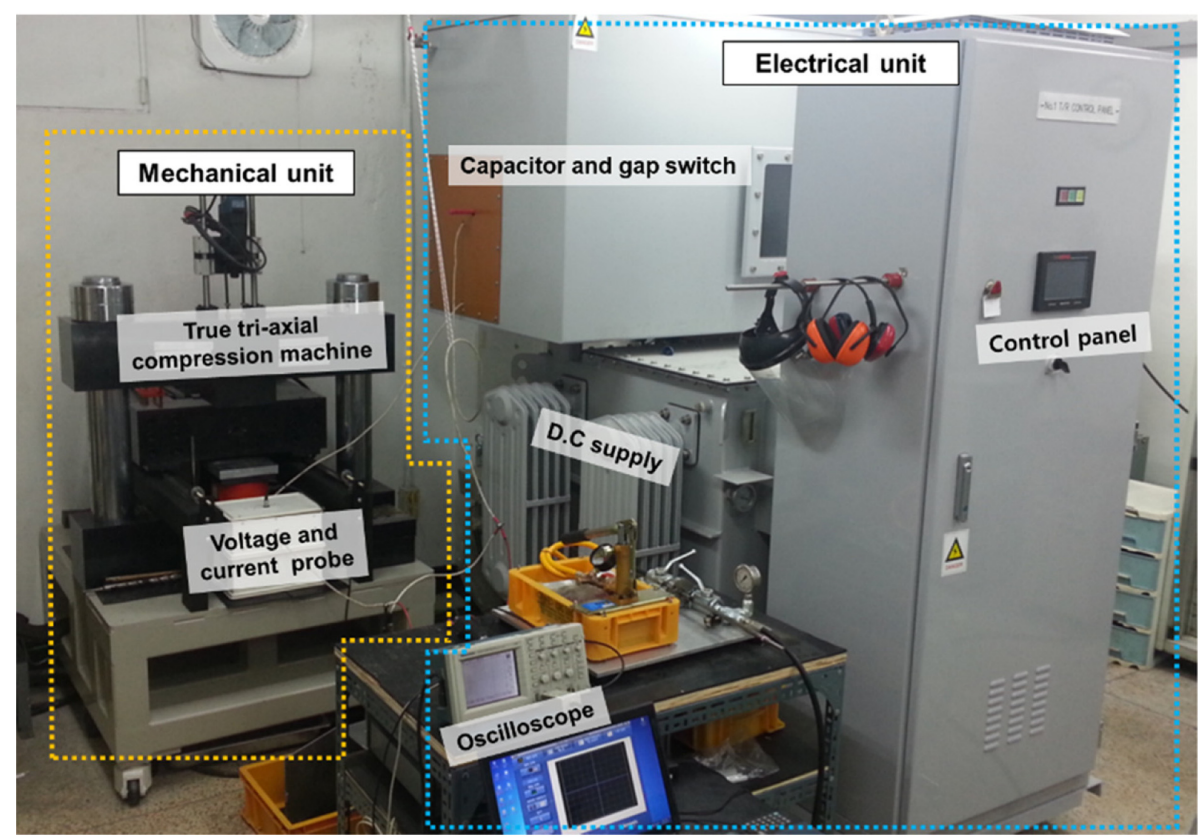

(b)

Figure 1. (a) Schematic diagram and (b) photograph of test apparatus for plasma blasting. ducted plasma blasting inside boreholes to increase oil productivity, and several patents were issued (Scott, 1978; Wesley, 1982). Plasma blasting is suitable for use in outer space because it is impossible to bring explosives in a spaceship to break rocks, and so plasma blasting is much safer (Best et al., 2008; Baltazar-Lopez et al., 2009). The method can also be useful in civil engineering or mining (Hamelin et al., 1993; Pronko et al., 1993). In general, explosives are difficult to handle safely and blasting by explosives sometimes causes vibration, although controlled blasting or smooth blasting which are rather expensive can control vibration. Plasma blasting is less dangerous and produces less vibration than blasting by explosives. Recently, fracturing technology by plasma blasting has been studied by some researchers for development of unconventional hydrocarbon resources (Maurel et al., 2010; Chen et al., 2012; Yan et al., 2016a, b); However, all these studies focused on breaking solid material by plasma blasting under the atmospheric pressure. No research has been conducted on the amount of energy needed to fracture rock under various stress conditions and the characteristics of fracture development by plasma blasting for specimens under various stress conditions.

In this study, laboratory-scale fracturing by plasma blasting was performed to investigate the possibility of using plasma blasting to fracture shale-gasbearing rock or rock for geothermal development. The experimental energy criterion for fracturing and the characteristics of fracture development in different stress conditions were examined. Artificial specimens were produced using cement mortar; natural rock (sandstone) specimens were also prepared. The characteristics of the plasma blasting apparatus were examined by measuring the discharge energy for different gap distances of the gap switch. The energies required to fracture cement mortar specimens under uniform pressure and the characteristics of fracture development were investigated. Specimens with three different principal stresses, representing the assumed in situ stress state, were fractured by plasma blasting to investigate the characteristics of fracture development in situ. Finally, proppant injection by plasma blasting and the effect of anisotropy of natural rock were examined.

\section{Experiment}

\section{Experimental Apparatus}

The test apparatus is composed of an electrical unit and a mechanical unit (Fig. 1). The electrical unit (EnerCons Inc., Seoul, Korea) consists of a power supply that converts AC power into DC power, a capacitor that stores electrical energy, a gap switch that controls the discharge voltage and instantaneously transfers electrical energy, and a blasting probe that 


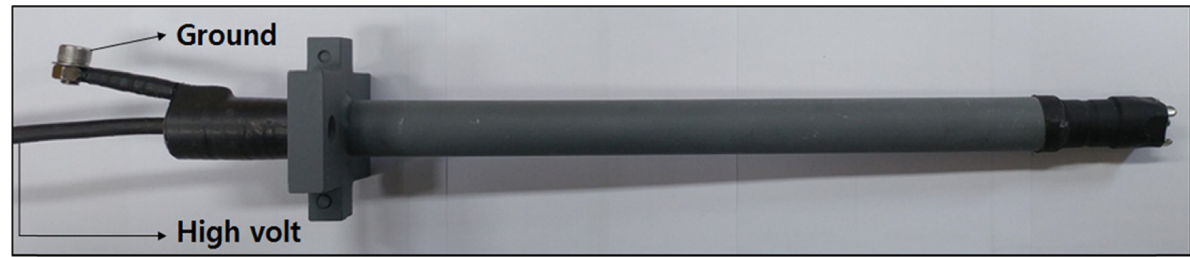

(a)

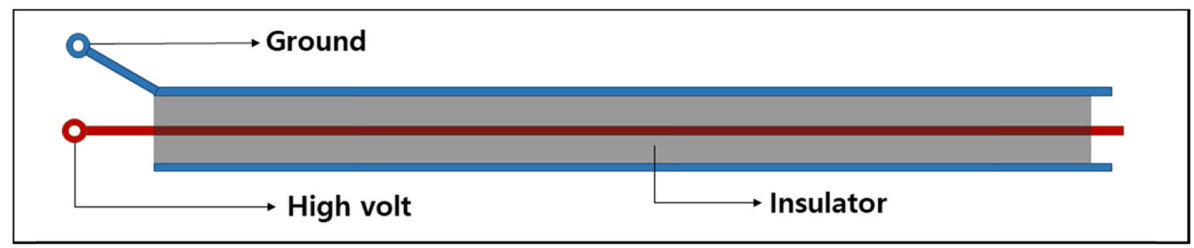

(b)

Figure 2. (a) Photograph and (b) cross-section of the blasting probe.

generates an electrical discharge inside the borehole. This type of electrical unit has also been used in previous studies (Touya et al., 2006; Best et al., 2008; Maurel et al., 2010; Chen et al., 2012; Zhu et al., 2013; Yan et al., 2016a, b). A power supply in which diodes and resistors are included supplies constant DC power to the capacitors. The capacitor has a capacitance of $200 \mu \mathrm{F}$ and can accumulate electrical energy up to a voltage of $22 \mathrm{kV}$. The discharge voltage can be controlled by the gap distance of the gap switch that is connected to the high-voltage line of the capacitor. The gap switch, which consists of two copper balls, is efficient and durable compared of other switches used for plasma blasting, such as gas, semiconductor and magnetic switches ( $\mathrm{Li}$ et al., 2017). The disadvantages of the gap switch are that discharge voltages cannot be controlled precisely and may be not the same at each blast, although the gap distances are equal. The blasting probe is made of steel and plastic. The outer steel tube of the probe serves as the ground electrode. A high-voltage electrode passes through the center of the probe and the space between the steel tube and the high-voltage electrode is filled with plastic insulation (Fig. 2). When electrical energy above a certain voltage level is charged into the capacitor, electrical energy is transferred instantaneously through the gap switch. The transferred electrical energy is discharged between the two electrodes at the end of the probe. The rock mass is broken by the strong shock wave and the volume expansion of fluid by rapid evaporation, which are produced by the electrical discharge.

A true-triaxial compression machine (AceOne Tech., Ansan, Korea) was used to pressurize the specimen. This machine has three independent pressurization systems along the $\mathrm{X}, \mathrm{Y}$, and $\mathrm{Z}$ directions

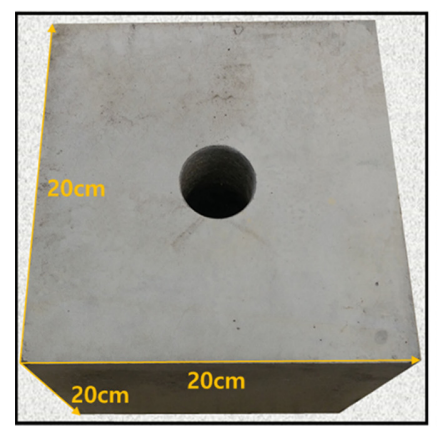

(a)

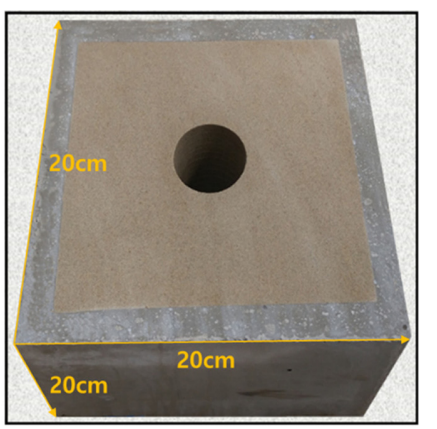

(b)
Figure 3. (a) Cement mortar specimen and (b) sandstone specimen.
(Fig. 1); thus, it can produce both uniform pressure conditions and the in situ stress conditions of an underground rock mass. The maximum load along each direction is $980 \mathrm{kN}$; therefore, for a cubic specimen with 20 -cm sides, the maximum normal stress along each direction is $25 \mathrm{MPa}$.

\section{Specimen Preparation}

Forty cubic specimens with 20 -cm sides were produced using cement mortar, which is a mixture of cement $(40 \%)$ and sand $(60 \%)$ (Fig. 3a). Cement mortar (GP-400, Hanilcement Co. Ltd., Korea) was easy to form into a cubic shape and the specimens made of cement mortar were homogeneous. If specimens were not homogeneous, the experimental results would be difficult to investigate because the results would be affected by specimen-specific characteristics. The cement mortar was mixed with water that was $15 \%$ of the cement mortar weight and solidified for 3 days in a stainless steel mold (AceOne Tech., Ansan Korea) manufactured with an accuracy of less than $0.5 \mathrm{~mm}$ in length. Subsequently, specimens were cured in water for more than one month to ensure specimen uniformity. Five rock specimens of yellowish-brown fine-grained quartz sandstone of Neoproterozoic age from the Sugetbrak Formation of the Aksu area, Tarim Basin, China were also prepared. In the sandstone, bedding planes are weakly developed. Because it was very difficult to cut rock specimens as exact cubes, sandstone blocks were cut as rough cubes with side lengths of about $18 \mathrm{~cm}$. Each of these specimens was placed in the center of a mold and the gaps between the sandstone and the mold were filled with cement mortar to produce exact cubes (Fig. 3b). Neither detachment nor breaking between the sandstone and the cement mortar were observed during pressurization and blasting of specimens. The compressive strengths of the cement mortar and sandstone specimens were 46.8 and $46.0 \mathrm{MPa}$ and the tensile strengths were 3.26 and $3.29 \mathrm{MPa}$, respectively. These compressive and tensile strengths of cement mortar and sandstone are similar to those of shale-gas-bearing rock (Fjaer and Nes, 2013). The porosity of the sandstone was $11.94 \%$, much higher than that of the cement mortar, which was $1.5 \%$ (Table 1).

\section{Experimental Procedures}

A borehole $3.2 \mathrm{~cm}$ in diameter was drilled at the center of the specimen. The specimen was placed in the true-triaxial compression machine and pressurized. Fluid (tap water) was injected into the borehole. The blasting probe was inserted into the central portion of the borehole and high-voltage electricity was discharged. The current and voltage were measured during discharge to analyze the electrical characteristics. The discharge voltage was determined from the voltage difference between two electrodes of the probe and the current was measured through the ground line along which the current returned to the capacitor. As the power supply was activated, electrical energy began to accumulate in the capacitor and the voltage increased. When the voltage in the capacitor became higher than the voltage level that would pass 
Table 1. Physical and mechanical properties of cement mortar and sandstone samples

\begin{tabular}{|c|c|c|c|c|c|c|}
\hline & $\begin{array}{c}\text { Density } \\
\left(\mathrm{g} / \mathrm{cm}^{3}\right)\end{array}$ & $\begin{array}{c}\text { Porosity } \\
(\%)\end{array}$ & $\begin{array}{c}\text { Tensile strength } \\
(\mathrm{MPa})\end{array}$ & $\begin{array}{c}\text { Uniaxial compressive } \\
\text { strength }(\mathrm{MPa})\end{array}$ & $\begin{array}{c}\text { Cohesion } \\
(\mathrm{MPa})\end{array}$ & $\begin{array}{c}\text { Friction Angle } \\
\left({ }^{\circ}\right)\end{array}$ \\
\hline Cement mortar & 2.03 & 1.50 & 3.26 & 46.80 & 11.32 & 39.3 \\
\hline Sandstone & 2.29 & 11.94 & 3.29 & 46.02 & 9.78 & 47.2 \\
\hline
\end{tabular}

through the gap between two copper balls in the gap switch, a plasma blast took place between the two electrodes at the end of the blasting probe.

Three types of experiment were carried out. First, specimens were pressurized by uniform pressure and fractured by plasma blasting to determine how discharge energy varied with uniform pressure. Characteristics of fracture development for different uniform pressures and discharge energies were investigated. Second, specimens were pressurized by three different principal stresses, which represented the assumed in situ stress conditions, and were fractured by plasma blasting. Differences in fracture development under different stress conditions and discharge energies were examined. Finally, experiments on proppant injection, verification of fracturing and the effects of anisotropy in fracturing of natural rock were carried out. Proppant injection was examined by plasma blasting together with water mixed with proppants. Quartz glass beads with a diameter of less than $400 \mu \mathrm{m}$ were used as proppants. As the glass beads were transparent, they were not easy to recognize within fractures; hence, they were dyed by red ink. Hydraulic conductivity of specimen was measured by the double packer test before and after plasma blasting to verify fracturing. A section of borehole was sealed off by packers above and below the test section and water was pumped into the test section. The hydraulic conductivity, K, was calculated:

$$
\begin{aligned}
& K=\frac{Q}{2 \pi L H} \ln \left(\frac{L}{r}\right), \quad \text { if } \frac{L}{r}>10 \\
& K=\frac{Q}{2 \pi L H} \sinh ^{-1}, \quad \text { if } 10>\frac{L}{r}>1
\end{aligned}
$$

where $\mathrm{Q}$ is flow rate, and $\mathrm{r}$ is the radius of borehole. $\mathrm{L}$ is the test section, and $\mathrm{H}$ is increase in head compared with that at rest (Hamm et al., 2007). In this test, $\mathrm{L}$ was $10 \mathrm{~cm}$ and $\mathrm{r}$ was $1.6 \mathrm{~cm}$. Thus, equation (2) was used in calculation of hydraulic conductivity.

\section{Discharge Energy}

The discharge voltage was controlled by the gap distance. The greater the gap distance is, the higher the voltage is. Plasma blasting began with a gap distance of $1.0 \mathrm{~mm}$. Gap distances increased for each successive plasma blast at $0.5-\mathrm{mm}$ intervals to a maximum of $4.0 \mathrm{~mm}$ and the discharge voltage was measured during each blasting. Blasting was carried out at least twice for each gap distance and average voltages were calculated. When the gap distance was $1.0 \mathrm{~mm}$, the average discharge voltage was $5 \mathrm{kV}$; when the gap distance was $4.0 \mathrm{~mm}$, the average voltage was $13 \mathrm{kV}$. As the gap distances increased, the average discharge voltages increased linearly (Fig. 4). The coefficient of determination for the regression line $\left(\mathrm{R}^{2}\right)$ was as high as 0.98 . However, as shown in Fig. 4, the discharge voltages were not equal although the gap distances were identical; for example, there was a voltage dif-

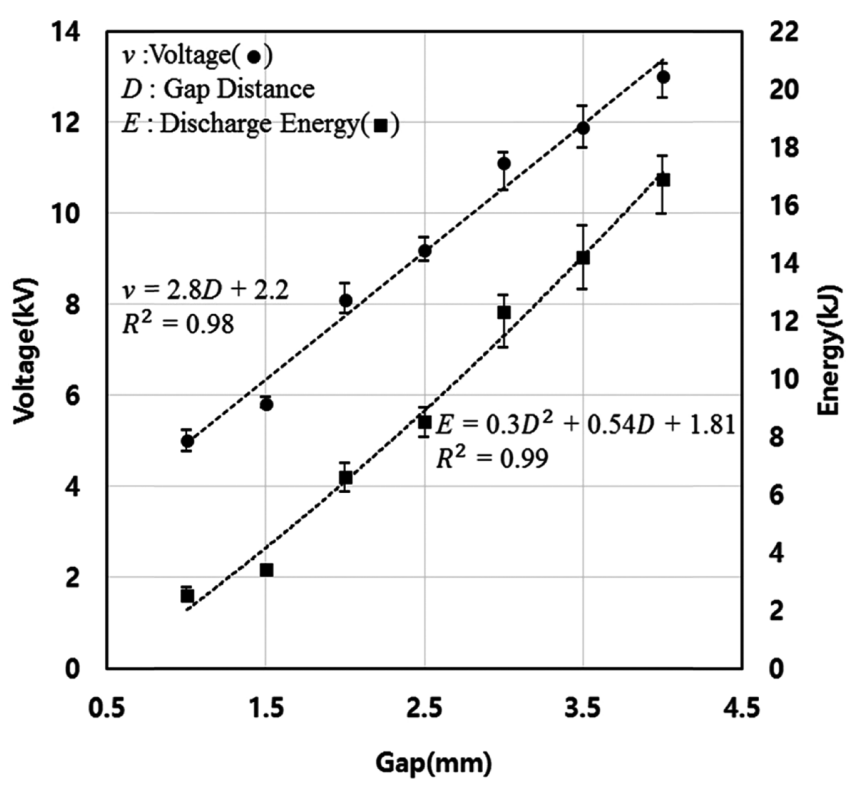

Figure 4. Relationships between discharge voltage and gap distance, and between energy and gap distance.

ference of $0.91 \mathrm{kV}$ between different blasting experiments when the gap distance was $3.5 \mathrm{~mm}$. This is because the conditions of the copper ball surfaces, humidity and electrical conductivity of fluid might have been different for each blast. As almost all the electrical energy accumulated in the capacitor is discharged during plasma blasting, the electrical energy in the capacitor may be equal to the discharge energy (Yan et al., 2016a). The electrical energy accumulated in the capacitor is calculated from the capacitance of the capacitor and the discharge voltage (Eq. 3).

$$
E=\frac{1}{2} c v^{2}
$$

where $\mathrm{E}$ is the discharge energy, $\mathrm{c}$ is the capacitance of the capacitor and $v$ is the discharge voltage. When the gap distance was $1.0 \mathrm{~mm}$, the average discharge voltage was $5.0 \mathrm{kV}$ and thus the energy was 2.5 $\mathrm{kJ}$. When the gap distance was $4 \mathrm{~mm}$, the average discharge voltage was $13 \mathrm{kV}$ and the energy was $16.9 \mathrm{~kJ}$. As the discharge energy is related to the square of the voltage, the energy increases as a parabolic curve (Fig. 4).

\section{Results and Discussion}

\section{Fracture Development under Uniform Pressure}

Shale gas formations may lie at shallow depth to very deep underground; therefore, the in situ stress may be high and the energy needed to 


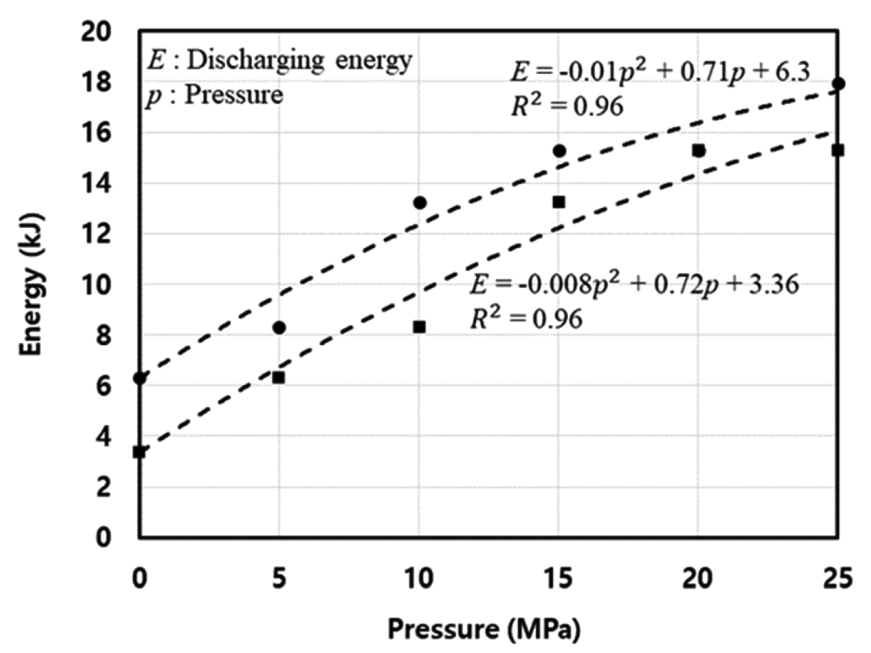

Figure 5. Energies needed to fracture cement mortar specimens under uniform pressure. Solid circles represent energies that fractured the specimen; solid rectangles are energies that did not fracture specimens at each level of uniform pressure. Dashed lines are best-fit lines. The upper line indicates the upper limit of zone and the lower line indicates the lower limit of zone for fracturing of a cement mortar specimen by plasma blasting.

fracture the shale will be higher than that required under atmospheric pressure. However, almost all research on plasma blasting in resources engineering, civil engineering and environmental science has been carried out under atmospheric pressure (Chen et al., 2012; Yan et al., 2016b). Therefore, plasma blasting tests on specimens under stressed conditions are necessary to apply plasma blasting in shale gas development.

Several plasma blasting tests were performed for cement mortar specimens under uniform pressures of 0-25 $\mathrm{MPa}$ to determine the energy needed to fracture specimens under different uniform pressures, and to characterize fracture development (Fig. 5). Because no research had been done on how much energy is needed to fracture cement mortar specimens under different uniform pressures, trial and error was used to determine the energy. Plasma blasting with a certain energy level was conducted for a specimen under a given uniform pressure. If the specimen was not fractured, it was discarded and a new specimen was prepared. Plasma blasting with higher energy than before was conducted again under the same uniform pressure. If the specimen fractured, plasma blasting at a higher uniform pressure was carried out. The discharge energy measured by this method might be over-estimated because the gap distance increased at $0.5 \mathrm{~mm}$ intervals, so the energy increment was large at each step. For example, when the pressure was $10 \mathrm{MPa}$, the specimen did not fracture with a gap distance of $2.5 \mathrm{~mm}$ and a discharge energy of $8.3 \mathrm{~kJ}$ (Fig. 5). The next test was conducted on a new specimen with a gap distance of $3.0 \mathrm{~mm}$ and a discharge energy of $13.2 \mathrm{~kJ}$; under these conditions, fractures developed. At a pressure of $10 \mathrm{MPa}, 13.2 \mathrm{~kJ}$ was determined as the energy necessary to fracture the specimen. However, $13.2 \mathrm{~kJ}$ is not the minimum energy to fracture the specimen; instead, the specimen might have fractured at $8.4 \mathrm{~kJ}$, which is $0.1 \mathrm{~kJ}$ higher than the value for one step before. Therefore, a zone, rather than a line, was determined. In Fig. 5, the upper line indicates the highest energy and the lower line represents the lowest energy for fracturing of a cement mortar specimen by plasma blasting. The energy needed to fracture the cement mortar specimen may be located between these two lines (Fig. 5). Because plasma blasting is intended for shale gas development, the energy was determined from fractures in the specimen that were sufficiently long to be identified visually. This may be another factor resulting in overestimation of the energy necessary for fracturing.

As uniform pressures increased, both the upper limit and the lower limit required for fracturing increased. Energy increased somewhat rapidly up to a pressure of about $15 \mathrm{MPa}$, but the increment rate decreased gradually as pressure increased. The best-fit curves are parabolic, and both $\mathrm{R}^{2}$ values are 0.96 . These curves represent the energy necessary for fracturing of cement mortar specimens under uniform pressure. The area below the low limit curve may represent stability; that above the high limit curve represents possible specimen failure.

Three plasma blasts with almost the same energy and different uniform pressures were performed on cement mortar specimens to investigate the variation of fracture development with pressure (Fig. 6). The pressures were 5, 10 and $20 \mathrm{MPa}$ and the discharge energies were $14.2-14.8 \mathrm{~kJ}$, which are the minimum energies required to break the specimen under a pressure of $20 \mathrm{MPa}$. When the pressure was $5 \mathrm{MPa}$,

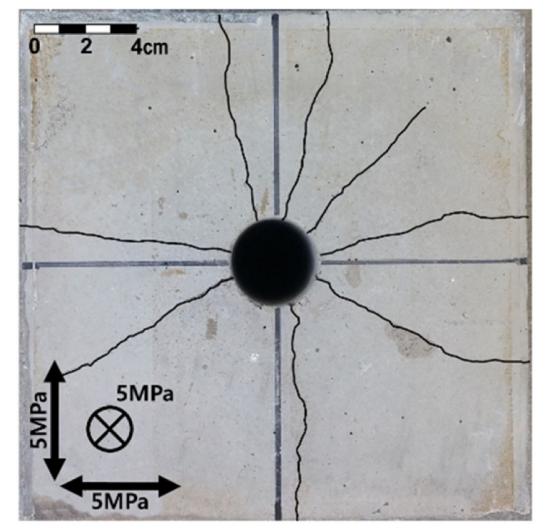

(a)

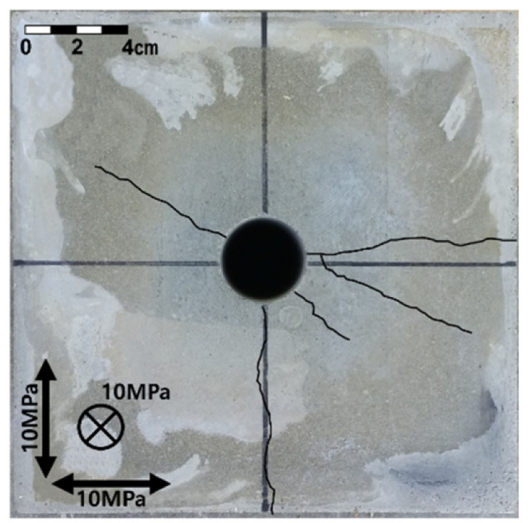

(b)

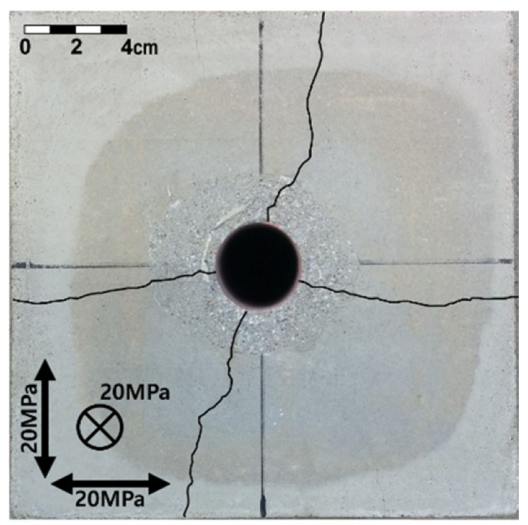

(c)

Figure 6. Different patterns of fracture development with similar discharge energy but different uniform pressures. The gap distance was 3.5 mm for all three specimens but the discharge energies were 14.2-14.8 kJ. The uniform pressures were (a) 5 MPa, (b) 10 MPa and (c) 20 MPa. Thin solid lines are fractures. 
eight radial fractures developed (Fig. 6a). Six of these fractures reached the sides of the specimen and the other two fractures were longer than $5 \mathrm{~cm}$. Fractures were distributed rather evenly in the specimen, though three fractures developed in the right upper quadrant. This may have occurred because of an uneven pressure distribution within the specimen. At a pressure of $10 \mathrm{MPa}$, five fractures formed within the specimen. Two fractures reached the sides of the specimen, but two were shorter. One fracture did not initiate from the wall of the borehole. When the pressure was $20 \mathrm{MPa}$, four fractures developed in the central portions of the sides of the specimen, all of which reached the side walls of the specimen. These results indicate that, for constant discharge energy, fewer fractures will be developed at higher uniform pressure.

\section{Fracture Development under In situ Stress}

The in situ stress generally has three different principal stresses. Plasma blasting tests were performed for cement mortar specimens to which three different stresses were applied using the true tri-axial compression machine. The three principal stresses were $\sigma_{1}=15 \mathrm{MPa}$, $\sigma_{2}=10 \mathrm{MPa}$, and $\sigma_{3}=7 \mathrm{MPa}$ (Fig. 7); $\sigma_{3}$ was fixed as the vertical stress and $\sigma_{1}$ and $\sigma_{2}$ as two horizontal stresses. Then, hydraulic fracturing always makes horizontal fractures which is perpendicular to the minor principal stress. Since the intermediate principal stress is also a factor to control fractures (Ali et al., 2015), two different stress states on the plane perpendicular to the borehole axis were applied to specimens to investigate whether the fracturing direction and characteristics of fracture development were affected by the stress state. As a horizontal hole was drilled for plasma blasting, the plane perpendicular to the borehole axis was a vertical plane. If a borehole was drilled parallel to the $\sigma_{1}$ direction, the stresses acting on the plane were the intermediate and the minor principal stresses and were 10 and $7 \mathrm{MPa}$. The differential stress, which is the difference between stresses, would be $3 \mathrm{MPa}$ (Fig. 7a). For a borehole parallel to the $\sigma_{2}$ direction, the stresses acting on the plane were the major and the minor principal stresses and were 15 and $7 \mathrm{MPa}$. The differential stress was $8 \mathrm{MPa}$ (Fig. 7b).

A specimen with a differential stress of $3 \mathrm{MPa}$ was fractured by

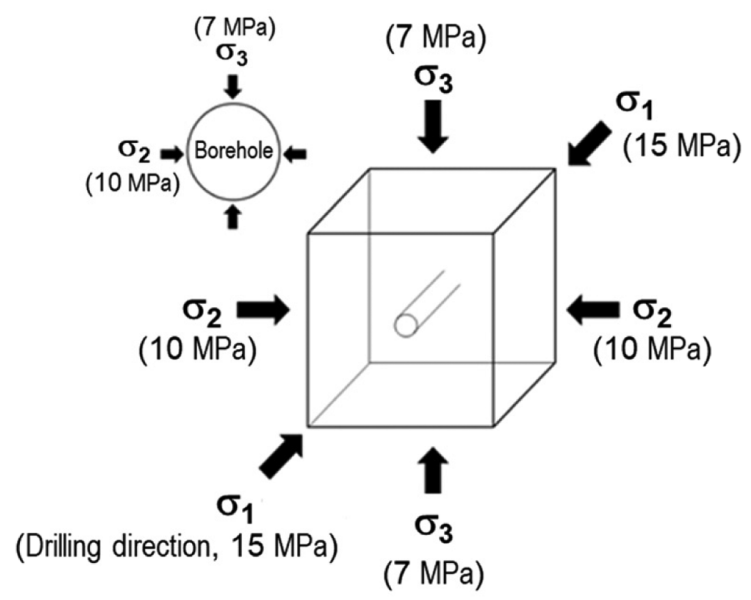

(a) plasma blasting with a discharge energy of $11.9 \mathrm{~kJ}$ since the average of the three principal stresses was $10.7 \mathrm{MPa}$ and the minimum energy required to fracture the specimen with uniform pressures of $10.7 \mathrm{MPa}$ was about $11.0 \mathrm{~kJ}$ (Fig. 5). The gap distance between the two copper balls was $3.0 \mathrm{~mm}$. Three fractures propagated from the borehole. The dominant fracture was almost perpendicular to the minor principal stress direction, the same result as with hydraulic fracturing (Riu et al., 2017). This fracture reached the side of the specimen. The two other fractures were short and oblique to the minor stress direction (Fig. 8a). A specimen with a differential stress of $8 \mathrm{MPa}$ was fractured by plasma blasting with a discharge energy of $13.2 \mathrm{~kJ}$. The discharge energy was different from the energy discharged in the previous experiment, although the gap distance between the copper balls was the same. This is because of slight differences in factors such as surface conditions of the copper balls and electrodes of blasting probe, humidity, and a slight difference in fluid conductivity. Two fractures were developed and reached the side of the specimen, and were almost perpendicular to the direction of the minor stress. These fractures were distinct, long and almost straight because of higher energy and higher differential stress than the previous experiment in Fig. 8a.

Plasma blasting was performed with the same stress conditions as Fig. 8, but higher discharge energy. The gap distance between the copper balls was $4.0 \mathrm{~mm}$ and the discharge energy was $18.5 \mathrm{~kJ}$. With a differential stress of $3 \mathrm{MPa}$, seven fractures formed (Fig. 9a). Four fractures propagated from the borehole to the sides of the specimen; two fractures were perpendicular to the minor principal stress, but two were parallel to the minor principal stress and perpendicular to the intermediate principal stress direction, which yielded different results from hydraulic fracturing. Three fractures were short and almost perpendicular to the minor principal stress direction: two of these propagated from the borehole wall, but one initiated within the specimen. When the differential stress was $8 \mathrm{MPa}$, five fractures developed with a discharge energy of $18.6 \mathrm{~kJ}$ (Fig. 9b). Three fractures were long enough to reach the sides of the specimen, of which two were perpendicular to the minor stress. The other two fractures were short and oblique to the minor stress. No fracture perpendicular to the major principal stress were developed.

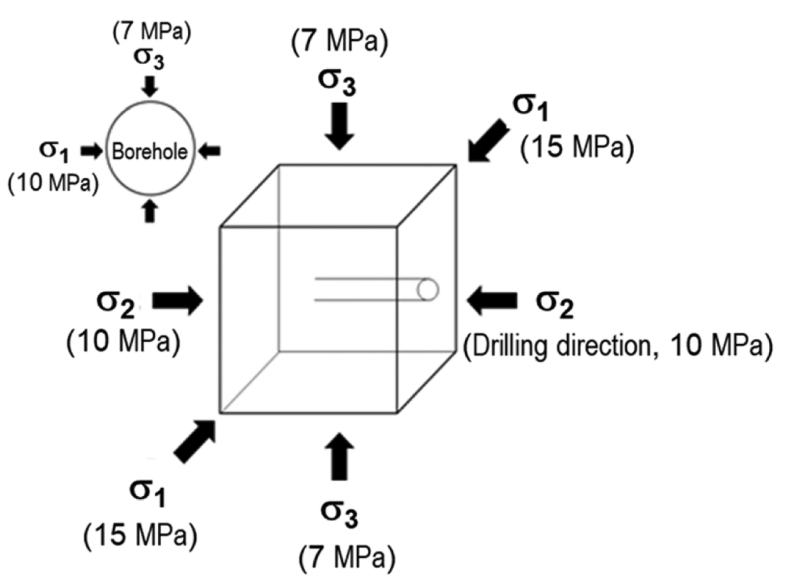

(b)

Figure 7. The three principal stresses applied to the specimens. (a) If the borehole is drilled along the $\sigma_{1}$ direction, the two stresses on the plane perpendicular to the borehole axis are 10 and $7 \mathrm{MPa}$, and the differential stress is $3 \mathrm{MPa}$. (b) If the borehole is drilled along the $\sigma_{2}$ direction, the two stresses on the plane perpendicular to the borehole axis are 15 and $7 \mathrm{MPa}$, and the differential stress is $8 \mathrm{MPa}$. 


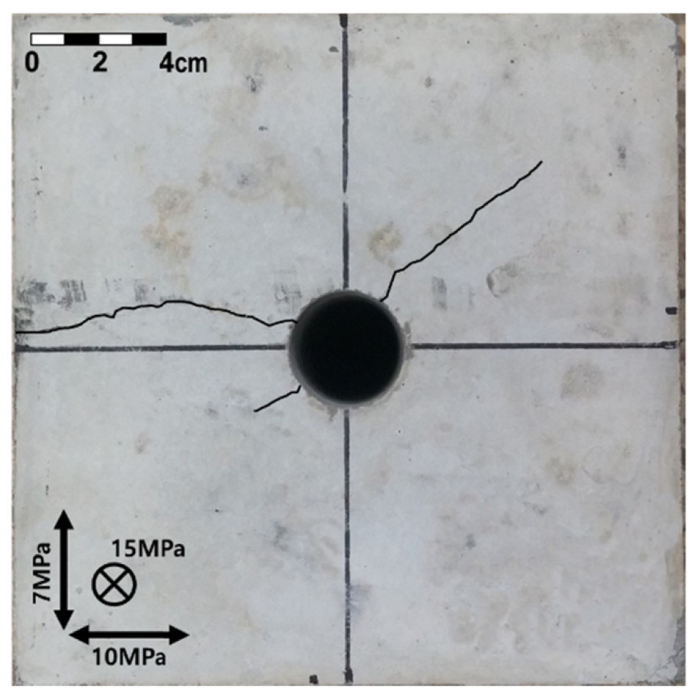

(a)

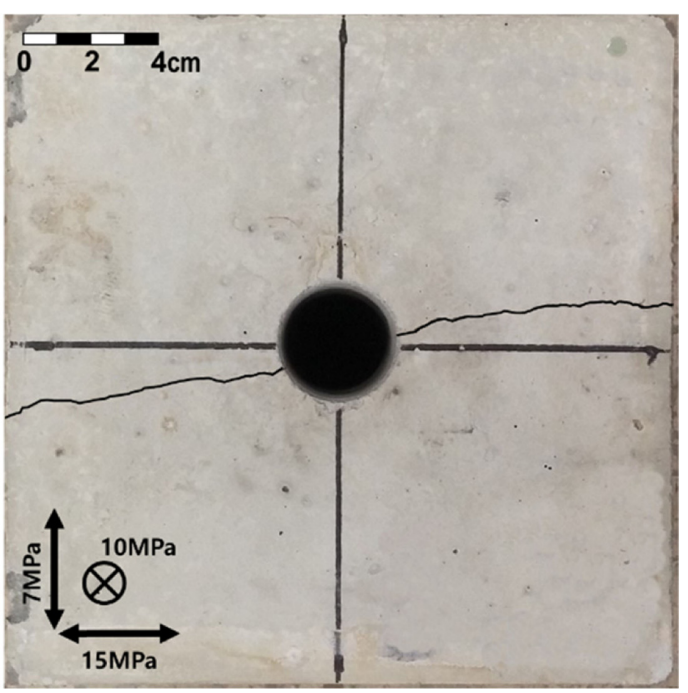

(b)

Figure 8. Characteristics of fracture development for (a) a differential stress of $3 \mathrm{MPa}$ and a discharge energy of $11.9 \mathrm{~kJ}$, and (b) a differential stress of 8 MPa and a discharge energy of $13.2 \mathrm{~kJ}$. Thin solid lines are fractures.

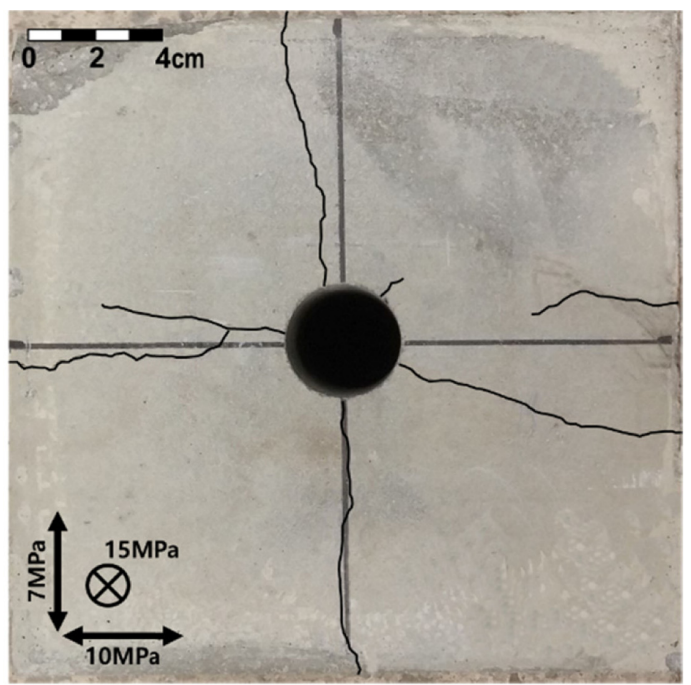

(a)

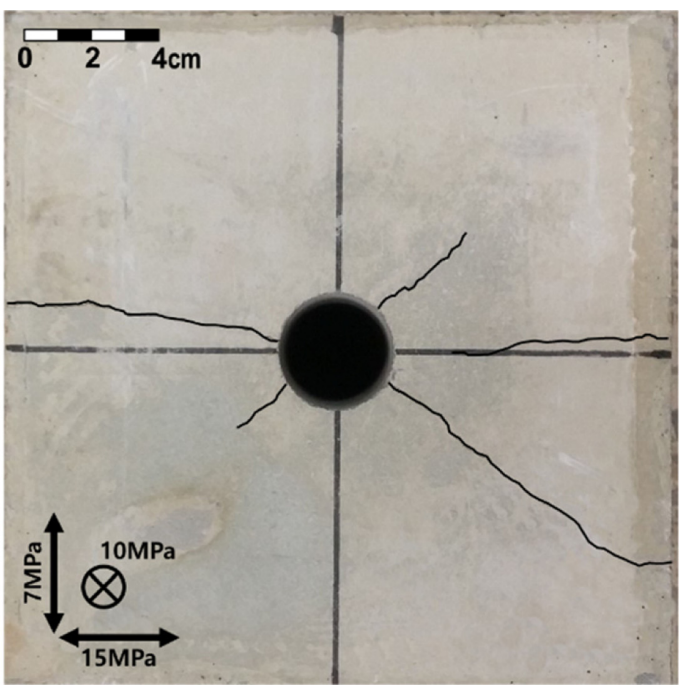

(b)

Figure 9. Characteristics of fracture development for (a) a differential stress of 3 MPa and a discharge energy of $18.5 \mathrm{~kJ}$, and (b) a differential stress of $8 \mathrm{MPa}$ and a discharge energy of $18.6 \mathrm{~kJ}$. Thin solid lines are fractures.

All these results indicate that the dominant fracture direction was perpendicular to the minor principal stress if the specimen was fractured by plasma blasting with the minimum discharge energy, which is the same result as the hydraulic fracturing. However, additional fractures propagated oblique to the minor stress direction when the differential stress was low. These were secondary fractures and usually short. When the differential stress was high, only one pair of fractures developed along the direction perpendicular to the minor stress. As the discharge energy increased, the number of fractures also increased. When the differential stress was low and the discharge energy was high, many fractures with a variety of directions formed. Some fractures were perpendicular to the minor stress, but some were perpendicular to the intermediate stress, which was different result from hydraulic fractur- ing. This is because fracturing mechanism by plasma blasting is different from that of hydraulic fracturing. In plasma blasting, the strong shock wave and the volume expansion of fluid by rapid evaporation are the main sources of fracturing. When the differential stress was high and the discharge energy was also high, a pair of distinct and long fractures perpendicular to the minor stress as well as fractures oblique to the major stress direction were developed. This is because fractures are difficult to propagate along the direction perpendicular to the major stress. When plasma blasting is applied for fracturing of shale-gas-formation, these results indicate that horizontal drilling along the major principal stress direction and plasma blasting with higher energy may develop more fractures. 


\section{Multiple Blasting in One Hole}

When a cement mortar specimen was fractured under three principal stresses of $\sigma_{1}=25 \mathrm{MPa}, \sigma_{2}=20 \mathrm{MPa}$ and $\sigma_{3}=17 \mathrm{MPa}$ and a discharge energy of $10.5 \mathrm{~kJ}$, three short fractures without any preferred orientation were developed (Fig. 10a). Since the average of three stresses were about $21 \mathrm{MPa}$ and the minimum energy for fracturing specimen was about $14.5 \mathrm{KJ}$ with uniform pressure of $21 \mathrm{MPa}$ (see Fig. 5), the discharge energy of $10.5 \mathrm{KJ}$ is much lower than the minimum discharge energy. The two stresses in the plane perpendicular to the borehole axis were 20 and $17 \mathrm{MPa}$; thus, the differential stress was $3 \mathrm{MPa}$. Three short fractures were developed because of low blasting energy under high stresses. One fracture was perpendicular to the minor stress but two fractures were perpendicular to the intermediate stress. This phenomenon which is similar to the fracturing under uniform pressure may be caused because of low differential stress. If plasma blasting were to be applied to fracturing of shale gas formations or formation for geothermal energy development, long fractures should be produced to increase the productivity of gas or hot water. As described in the previous section, a higher discharge energy can produce more and longer fractures; however, a higher energy can also increase the possibility of borehole collapse because plasma blasting develop rapid volume increase of fluid by evaporation, like explosives. A second plasma blast was applied to the same specimen with the same stress and energy as the first blast. Blasting produced one additional fracture and lengthened the pre-existing fractures (marked in red in Fig. 10b). When the specimen was fractured again by a third blast, the three fractures from the first blast became longer and reached the side of the specimen (Fig. 10c). This result indicates that multiple lowenergy blasts will produce the same fractures as a high discharge energy with low possibility of borehole collapse.

\section{Proppant Injection}

As fractures closed if water injection stopped after hydraulic fracturing because of the in situ stress, fractures produced by plasma blasting also closed and perfectly matched due to stresses applied to the specimen. Proppants are usually injected into fractures during hydraulic fracturing to keep the fractures open. Well-rounded, spherical and tightly graded natural sands and manufactured ceramics ranging in sizes from $100 \mu \mathrm{m}$ to $2 \mathrm{~mm}$ are usually used as proppants (Smith and Montgomery, 2015). Although proppants are easily injected into fractures by hydraulic fracturing, because such fracturing provides a steady flow for a long duration into the fractures, it is not certain whether proppants will be injected into fractures by plasma blasting because the blasting produces an instantaneous shock wave and volume increase.

To test this, plasma blasting was performed on cement mortar specimens with water mixed with proppants. The stresses on the specimen were $\sigma_{1}=15 \mathrm{MPa}, \sigma_{2}=10 \mathrm{MPa}$ and $\sigma_{3}=7 \mathrm{MPa}$. The stresses in the plane perpendicular to the borehole axis were $\sigma_{1}=15 \mathrm{MPa}$ and $\sigma_{3}$ $=7 \mathrm{MPa}$; hence, the differential stress was $8 \mathrm{MPa}$. The discharge energy was $13.1 \mathrm{~kJ}$. Only two fractures propagated from the borehole and were almost perpendicular to the minor stress direction on the plane, the same result as with a differential stress of $8 \mathrm{MPa}$ (Fig. 8b, Fig. 11). After plasma blasting and removal of stress, epoxy was injected into the fractures by placing the specimen, with the borehole filled

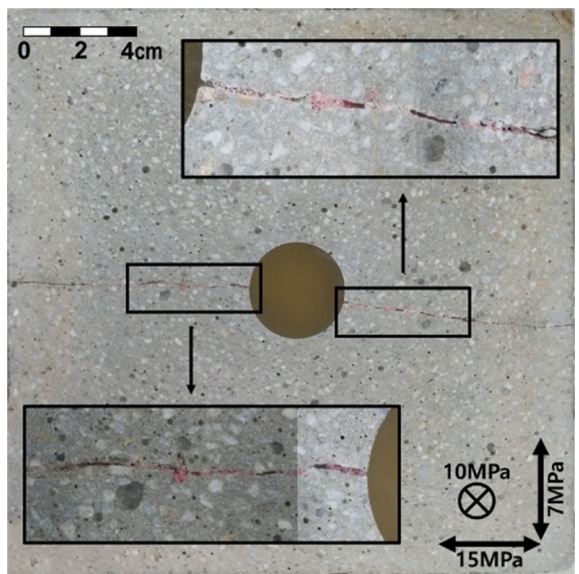

Figure 11. Photographs showing proppant injection by plasma blasting. The differential stress was 8 MPa and the discharge energy was $13.1 \mathrm{~kJ}$. The red coloration inside fractures is injected proppants.

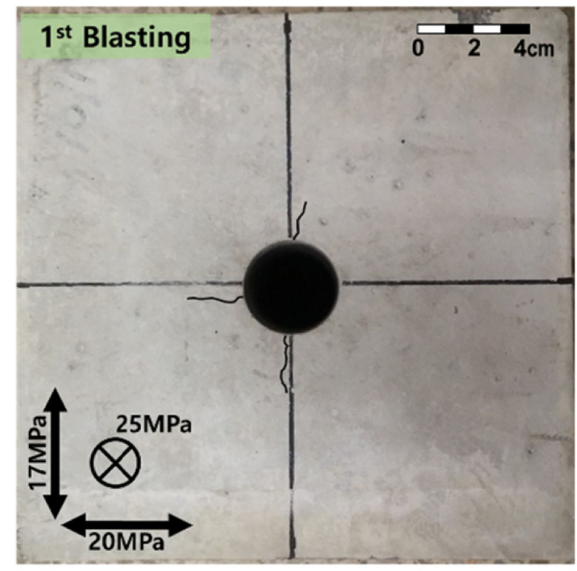

(a)

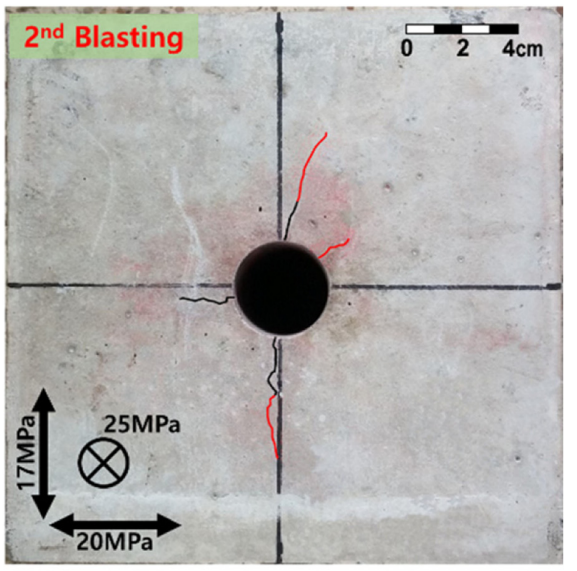

(b)

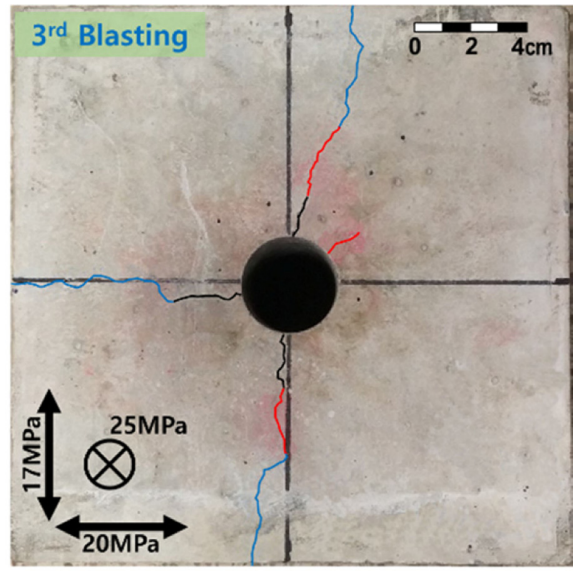

(c)

Figure 10. Characteristics of fracture development caused by multiple plasma blasts in one specimen. The differential stress was 3 MPa and the discharge energy was $10.5 \mathrm{~kJ}$. (a) Fracturing from the first blast (black), (b) fracturing from the second blast (red), and (c) fracturing from the third blast (blue). 
with epoxy, into a vacuum chamber. After solidification of the epoxy, the specimen was cut into 5-cm-thick slabs to check whether the proppants had penetrated the fractures. The very thin red coloration within fractures in Fig. 11 are injected glass beads. The glass beads penetrated about half of the whole fracture length. This short length of penetration was caused by the instantaneous shock wave and volume increase. Other methods, such as a continuous water supply with pressure during blasting or multiple blasting, will be required for deep penetration of proppants.

\section{Verification of Fracturing}

Fracturing by plasma blasting can be directly recognized by visual inspection of specimens in laboratory tests; however, in situ fracturing is difficult to detect and so fracturing should be investigated by indirect methods. Hydraulic conductivity measurement of the rock is one of the most efficient methods of fracturing verification (Hamm et al., 2007).

The hydraulic conductivity of a cement mortar specimen was measured by the double packer test before and after plasma blasting to verify the presence of fracturing. Stresses of $\sigma_{2}=\sigma_{3}=5 \mathrm{MPa}$ in the plane perpendicular to the borehole axis were applied to the specimen before plasma blasting and a packer test was conducted in the borehole. The continuously injected water for 10 minutes was $0.097 \mathrm{~cm}^{3}$ under the pressure of $3 \mathrm{MPa}$. The hydraulic conductivity of the specimen calculated by equation (2) was $1.62 \times 10^{-10} \mathrm{~cm} / \mathrm{sec}$. Stresses of $\sigma_{1}$ $=15 \mathrm{MPa}, \sigma_{2}=10 \mathrm{MPa}$ and $\sigma_{3}=7 \mathrm{MPa}$, for which the differential stress on the plane perpendicular to the borehole axis was $8 \mathrm{MPa}$, were applied to the specimen, which was blasted by plasma with a discharge energy of $14.5 \mathrm{~kJ}$ and fluid mixed with proppants. One pair of fractures that reached to the sides of the specimen was observed (Fig. 11). Hydraulic conductivity was measured again under the same stress conditions as the previous measurement. The injected water for 10 minutes was $473.4 \mathrm{~cm}^{3}$ under the pressure of $3 \mathrm{MPa}$ and hydraulic conductivity was found to be $7.85 \times 10^{-7} \mathrm{~cm} / \mathrm{sec}$ by Eq. (2). Thus, the hydraulic conductivity after blasting was almost four orders of magnitude greater

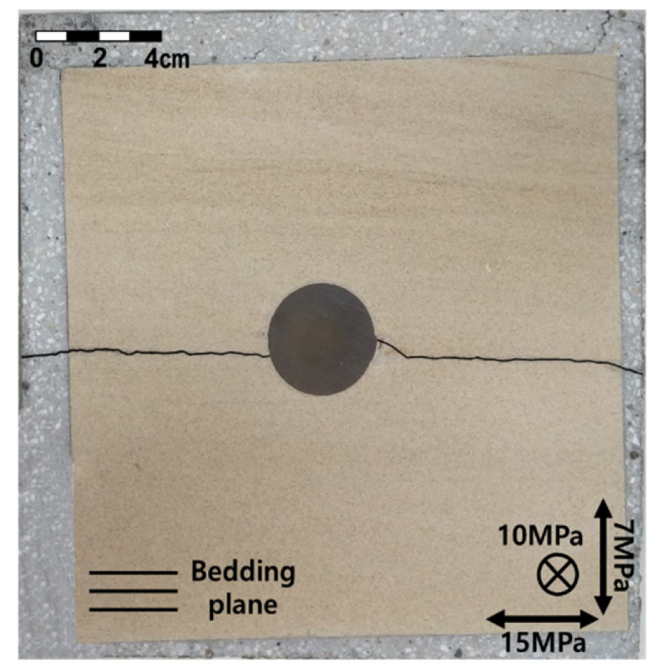

(a) than that before blasting, indicating that measurement of hydraulic conductivity is an efficient method for verification of fracturing.

\section{Rock Specimen Fracturing}

As the cement mortar specimens are made of homogeneous isotropic material, their physical and mechanical properties are different from those of natural shale, which is usually anisotropic and inhomogeneous. Obtaining shale specimens large enough for use in the true tri-axial compression machine is very difficult; therefore, sandstone was selected instead of shale. The boreholes for plasma blasting were drilled along the direction parallel to the bedding plane to investigate the influence of the bedding plane, because it is usually a plane of weakness. The two stresses in the plane perpendicular to the borehole axis were 15 and $7 \mathrm{MPa}$, and the differential stress was $8 \mathrm{MPa}$. The discharge energy was $16.5 \mathrm{~kJ}$. When the bedding plane was perpendicular to the minor stress direction, plasma blasting produced a pair of long and straight fractures parallel to the bedding plane and perpendicular to the minor stress direction (Fig. 12a). These fractures reached the side of the specimen, which is the same result as for a cement specimen with a differential stress of $8 \mathrm{MPa}$ (see Fig. 8b). However, when the bedding plane was parallel to the minor stress direction, a pair of short fractures almost perpendicular to the bedding plane and the minor stress direction were developed (Fig. 12b). One short fracture along the bedding plane, which was perpendicular to the major stress direction, also formed. This result indicates that the geological structures, such as bedding plane, are also a factor considered for fracturing by plasma blasting. However, stress states control the fracture directions more than the geological structure.

\section{Conclusions}

Laboratory-scale fracturing by plasma blasting was performed using cement mortar specimens and sandstone specimens to investigate the possibility of using plasma blasting to fracture shale-gas-bearing rock.

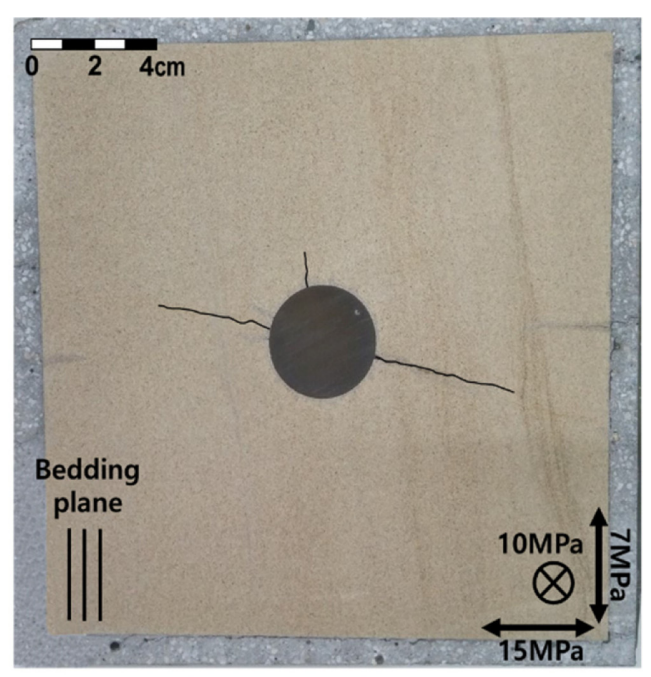

(b)

Figure 12. Patterns of fracture development in sandstone (a) when $\sigma_{3}$ was perpendicular to the bedding plane, and (b) when $\sigma_{3}$ was parallel to the bedding plane. The differential stress was $8 \mathrm{MPa}$ and the discharge energy was $16.5 \mathrm{~kJ}$. Thin solid lines are fractures. 
The variation of discharge voltage with gap distances was examined. Although the gap distances were the same, the discharge voltages were different because of differences in the copper ball surfaces, humidity and electrical conductivity of fluid. Therefore, average voltages were determined from several measurements at the same gap distance. The average discharge voltages increased linearly as gap distances increased and the discharge energy increased as a parabolic curve.

Plasma blasting was performed to investigate energy necessary for fracturing cement mortar specimens under uniform pressures, and a zone was determined, rather than a line. The upper line indicates the highest energy and the lower line represents the lowest energy for fracturing of a cement mortar specimen by plasma blasting. As uniform pressures increased, both the upper and the lower limits of energy required for fracturing increased as parabolic curves. When specimens were fractured by plasma blasting with almost the same energy but under different uniform pressures, fewer fractures were developed at higher uniform pressure.

Plasma blasting was carried out for cement mortar specimens to which three different stresses were applied to represent the assumed in situ stress conditions. Specimens were fractured under differential stresses of 3 and $8 \mathrm{MPa}$ and the characteristics of fracture development were investigated. Fractures were perpendicular to the minor stress direction if the specimen was fractured by plasma blasting with the minimum discharge energy. When the differential stress was low, additional fractures propagated along the direction oblique to the minor stress direction, but these were secondary fractures and usually short. When the differential stress was high, fractures formed along the direction perpendicular to the minor stress. As the discharge energy increased, the number of fractures also increased. When the differential stress was low and the discharge energy was high, many fractures along a variety of directions were developed. When the differential stress was high and the discharge energy was also high, some fractures oblique to the minor stress direction were generated. Borehole wall collapse was not observed when energy higher than the minimum required for fracturing was applied.

When a specimen was blasted several times by a fracturing energy that was lower than the minimum, the fractures developed were the same as those generated by a high discharge energy, without any possibility of the borehole collapse that might be caused by the higher discharge energy. Proppants were injected effectively into the fractures by plasma blasting. If continuous water supply with pressure during blasting or multiple blasting were used, proppants would penetrate deep into the fractures. The hydraulic conductivity of the specimen increased by four orders of magnitude after plasma blasting. When sandstone was blasted by plasma, the fracture orientation was strongly influenced by the geological structure.

All these results indicate that plasma blasting can be a possible method for fracturing in shale gas development. However, because plasma blasting has mostly been applied to laboratory-scale cement mortar specimens, further studies will be necessary to apply plasma blasting to fracking of shale-gas-bearing formations in field. Plasma blasting can also be used for fracturing geothermal reservoirs, but an apparatus with much higher energy than that used in this experiment will be necessary because igneous rock, such as granite, is stronger than cement mortar specimens and stress may be higher than that applied in this study. As mentioned, this study focuses mainly on laboratory- scale experiments involving a cement and mortar mixture. The results obtained here do not provide sufficient information to reasonably discuss the blasting behavior of metamorphic and igneous rocks. However, this topic should certainly be included in future studies and fieldbased applications.

\section{Acknowledgement}

This research was supported by Basic Science Research Program through the National Research Foundation of Korea (NRF) funded by the Ministry of Education(2019R1A6A1A03033167).

\section{References}

Ali, N.D., Kamran, G., Kaveh, A., and Yan, J., 2015, The effect of natural fracture dip and strike on hydraulic fracture propagation. International Journal of Rock Mechanics and Mining Sciences, v. 75, pp. 210-215.

Andres, U., 1994, Electrical disintegration of rock. Mineral Processing and Extractive Metallurgy Review, v. 14, pp. 87-110.

Baltazar-Lopez, M.E., Best, S., Brandhorst, H.W. Jr, and Burell, Z.M., 2009, Analysis and simulations of low power plasma blasting for processing lunar materials. $7^{\text {th }}$ International Energy Conversion Engineering Conference (IECEC), Denver, Colorado, pp. 4550.

Best, S., Baltazar-Lopez, M.E., Burell, Z.M., Brandhorst, H.W., Heffernan, M.E., and Rose, M.F., 2008, A low power approach for processing lunar materials. $6^{\text {th }}$ International Energy Conversion Engineering Conference (IECEC), Cleveland, Ohio, pp. 5710.

Chen, W., Maurel, O., Reess, T., Ferron, A.S.D., Borderie, C.L., PijaudierCabot, G., Rey-Bethbeder, F., and Jacques, A., 2012, Experimental study on an alternative oil stimulation technique for tight gas reservoirs based on dynamic shock waves generated by pulsed arc electohydraulic discharges. Journal of Petroleum Science and Engineering, v. 88-89, pp. 67-74.

Ellsworth, W.L., 2013, Injection-Induced earthquakes. Science, v. 341, 1225942.

Fjaer, E. and Nes, O.M., 2013, Strength anisotropy of Mancos shale. Proceedings of the 47th US Rock Mechanics and Geomechanics Symposium, San Francisco, California, 13-519.

Hamelin, M., Kitzinger, F., Pronko, S., and Schofield, G., 1993, Hard rock fragmentation with pulsed power. $9^{\text {th }}$ IEEE International Pulsed Power Conference, Albuquerque, New Mexico, v.1, pp. 11.

Hamm, S.Y., Kim, M.S., Cheong, J.Y., Kim, J.Y., Son, M., and Kim, T.W., 2007, Relationship between hydraulic conductivity and fracture properties estimated from packer tests and borehole data in a fractured granite. Engineering Geology, v. 92, pp. 73-87.

IEA, 2018, Energy outlook 2018, https://www.iea.org/weo2018.

Karpel-Vel-Leitner, N., Syoen, G., Romat, H., Urashima, K., and Chang, J.S., 2005, Generation of active entities by the pulsed arc electrohydraulic discharge system and application to removal of atrazine. Water Research, v. 39, pp. 4705-4714.

Kim, K., Ree, J., Kim, Y., Kim, S., Kang, S., and Seo, W., 2018, Assessing whether the $2017 \mathrm{M}_{\mathrm{w}}$ 5.4 Pohang earthquake in South Korea was an induced event. Science, v. 360, pp. 1007-1009.

Li, O.L.H., Chang, J.S., and Guo, Y., 2011, Pulsed arc electrohydraulic discharge characteristics, plasma parameters, and optical emission during contaminated pond water treatments. IEEE Electrical Insulation Magazine, v. 27, pp. 8-16.

Li, H., Lukanin, A., Tskhe, A., and Sosnovskiy, S., 2017, Multifunctional generator of high-voltage microsecond pulses. Journal of Electrostatics, v. 90, pp. $74-78$.

Maurel, O., Reess, T., Matallah, M., Ferron, A.D., Chen, W., Borderie, 
C.L., Pijaudier-Cabot, G., Jacques, A., and Rey-Bethbeder, F., 2010, Electrohydraulic shock wave generation as a means to increase intrinsic permeability of mortar. Cement and Concrete Research, v. 40, pp. 1631-1638.

Osborn, S.G., Vengosh, A., Warner, A.V., and Jackson, R.B., 2011, Methane contamination of drinking water accompanying gas-well drilling and hydraulic fracturing. Proceedings of the National Academy of Sciences, v. 108, pp. 8172-8176.

Perry, K. and Lee, J., 2007, Unconventional gas reservoirs: tight gas, coal seams, and shales. Working Document of The NPC Global Oil and Gas Study, Washington. Topic paper \#29.

Pronko, S., Schofield, G., Hamelin, M., and Kitzinger, F., 1993, Megajoule pulsed power experiments for plasma blasting mining applications. $9^{\text {th }}$ IEEE International Pulsed Power Conference, Albuquerque, New Mexico, v. 1, pp. 15.

Razavian, S.M., Rezai, B., Irannajad, M., and Ravanji, M.H., 2015, Numerical simulation of high voltage electric pulse comminution of phosphate ore. International Journal of Mining Science and Technology, v. 25, pp. 473-478.

Riu, H.S., Jang, H.S., and Jang, B.A., 2017, Investigation of fracture propagation in cement by hydraulic fracturing under the tri-axial stress condition. The Journal of Engineering Geology, v.27, pp.233-244 (in Korean with English abstract).

Scott, H.W., 1978, Extraction method and apparatus. U.S. Patent, No. $4,074,758$.

Smith, M.B. and Montgomery, C.T., 2015, Hydraulic fracturing. CRC Press, New York. 812p.

Touya, G., Reess, T., Pecastaing, L., Gibert, A., and Demens, P., 2006, Development of subsonic electrical discharges in water and measurements of the associated pressure waves. Journal of Physics D: Applied Physics, v. 39, pp. 5236-5244.

Wang, E., Shi, F., and Manlapig, E., 2011, Pre-weakening of mineral ores by high voltage pulses. Minerals Engineering, v. 24, pp. 455-462.

Wesley, R.H., 1982, Process and apparatus for electrohydraulic recovery of crude oil. U.S. Patent, No. 4,345,650.

Wu, C., Chu, J., Wu, S., and Hong, Y., 2019, 3D characterization of microbially induced carbonate precipitation in rock fracture and the resulted permeability reduction. Engineering Geology, v. 249, pp. 23-30

Yan ,F., Lin, B., Zhu, C., Guo, C., Zhou, Y., Zou, Q., and Liu, T., 2016a, Using high-voltage electrical pulses to crush coal in an air environment: An experimental study. Power Technology, v. 298, pp. 50-56.

Yan, F., Lin, B., Zhu, C., Zhou, Y., Liu, X., Gou, C., and Zou, Q., 2016b, Experimental investigation on anthracite coal fragmentation by highvoltage electrical pulses in the air condition: Effect of breakdown voltage. Fuel, v.183, pp. 583-592

Zhu, L., He, Z.J., Li, P., Xu, T.S., Zhao, H., Zhao, X.F., and Gao, Z.W., 2013, The research on the pulsed arc electrohydraulic discharge and its application in treatment of the ballast water. Journal of Electrostatics v.71, pp.728-733.

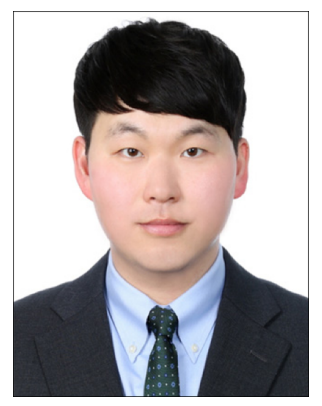

Heesung Ryu is doing his doctoral studies in Kangwon National University, Korea. He received his B.S. and M.S. degree from the Department of Geophysics, Kangwon National University, Korea. His research interests include geological engineering, rock material blasting and hydraulic fracturing method.
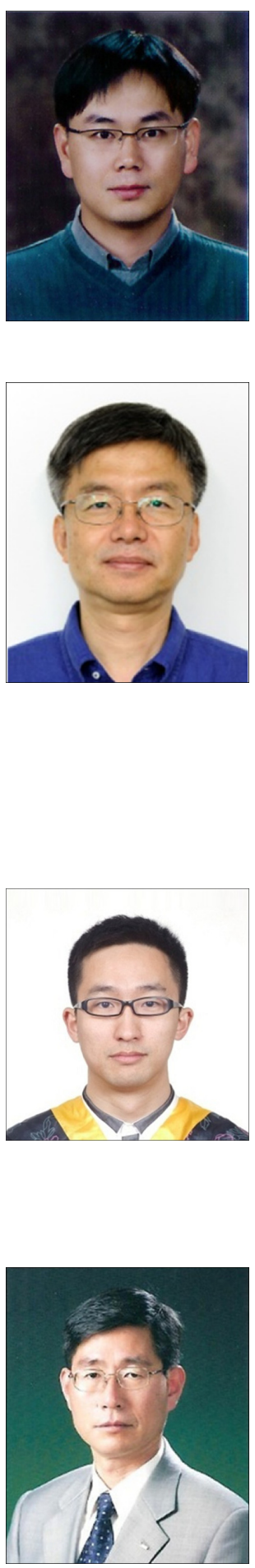

Hyun-Sic Jang is a researcher of the Department of Geophysics in Kangwon National University, Korea. He received his M.S. degree and Ph.D from Department of Geophysics, Kangwon National University, Korea. He was awarded the Best Paper Award by the Korean Society of Engineering Geology in 2016. He is an academic director of the Korean Society of Engineering Geology. His research interests include rock mechanics, geological engineering, rock material blasting and hydraulic fracturing method.

Bong Ju Lee is a full professor at the graduate school of Advanced Green Energy and Environment of Handong Global University, Pohang, Korea. He received the Ph.D degree in plasma physics from the University of Wisconsin, Madison, USA, in 1991. He held the positions Assistant/Associate Scientific Researcher at UC-Los Angeles and UC-San Diego for 6 years, and the Principal Researcher at the Convergent Plasma research Center, National Fusion Research Institute, Daejeon, Korea. His research interests include the applications of plasma and nuclear fusion. He was awarded Presidential Commendation for the advancement of science and technology in 2006 and awarded commendation by minister for an excellent venture entrepreneur in the era of creative economy in 2015 also.

Chuangzhou $\boldsymbol{W u}$ is a senior researcher of rock mechanics and rock engineering in Kangwon National University, Korea. He received his Ph.D. from Tongji University, China. He had been studying the biogrouting technology for underground space for three years in Nanyang Technological University, Singapore. His research interests focus on the long-term stability of underground structure in rock mass and mechanical and hydraulic behavior of rock fracture sealed/healed with biogrouts.

Bo-An Jang is a full professor of the Department of Geophysics in Kangwon National University, Korea. He received his Ph.D. degree from University of Wisconsin-Madison, USA in 1989. His current research topics are fracture development in rock and soil by plasma blasting, slope stability analysis, physical and mechanical properties of rock materials and characteristics of joint surface. He published more than 200 papers in journals and conferences. He had served as an Executive Committee Member and an Inspection Committee Member of the Geological Society of Korea, and as an Executive Committee Member, Vice President, and President of the Korean Society of Engineering Geology. He had also held the positions of Dean of International Affairs, Dean of Industrial Cooperation, and Dean of the College of Natural Sciences at Kangwon National University. He is currently the Vice President of International Association of Engineering Geology and Environment and the Director of the Key Laboratory for mitigation of geo-hazard in densely populated areas. 